\title{
CARACTERIZAÇÃO DE BIOCOMPÓSITOS PRODUZIDOS POR POLICONDENSAÇÃO DE L-ÁCIDO LÁCTICO EM HIDROGÉIS DE CELULOSE BACTERIANA
}

\author{
E. CIRIGO y P. ${ }^{1}$, L. M. PORTO ${ }^{1}$ \\ ${ }^{1}$ Universidade Federal de Santa Catarina, \\ Departamento de Engenharia Química e Engenharia de Alimentos \\ E-mail para contato: \{ericka, luismar\}@intelab.ufsc.br
}

\begin{abstract}
RESUMO - O poli(L-ácido láctico) (PLLA) é um material que apresenta boa biocompatibilidade, biodegradabilidade e suas propriedades the proporciona uma ampla gama de aplicações. Por sua vez, a celulose bacteriana (CB) é um biomaterial de alta pureza, biocompatível, com propriedades estruturais e mecânicas únicas, pelo que torna-se promissor o desenvolvimento de biocompósitos que integrem as características da CB e do PLLA. Para isto, L-ácido láctico foi policondensado dentro de hidrogéis de $\mathrm{CB}$, sem uso de catalisadores, gerando uma matriz polimérica no interior da rede de fibras de CB. A caracterização dos biocompósitos foi feita por Microscopia Eletrônica de Varredura (MEV), Espectroscopia no Infravermelho com Transformada de Fourier (FTIR) e Termogravimétria (Tg/DTg). No MEV observou-se a formação de uma massa com características similares às do PLLA puro e boa dispersão das fibras de CB. A análise termogravimétrica confirmou características próprias do PLLA, do mesmo modo o FTIR confirmou a formação do polímero.
\end{abstract}

\section{INTRODUÇÃO}

Os avanços tecnológicos nas áreas da medicina, engenharia e ciência dos materiais, possibilitou o desenvolvimento de materiais com as características necessárias para aplicações biomédicas (Gupta et al., 2007; John et al., 2007; Cheng et al., 2009; Jardini et al., 2010; Lopes et al., 2012). Os materiais usados em engenharia de tecidos devem ser biocompatíveis, biodegradáveis, de alta porosidade, com uma grande proporção superfície/volume para facilitar a adesão de células e promover seu crescimento, permitindo também a conservação das funções das células diferenciadas (Cheng et al., 2009; Lopes et al., 2012). Os biomateriais de origem natural mais usados são proteínas ou polissacarídeos; entretanto, os de origem sintética incluem metais, cerâmicas e compósitos de polímeros biodegradáveis. Dos biomateriais de origem natural, um dos mais promissores é a celulose bacteriana (CB), um polissacarídeo secretado extracelularmente, produzido por diversas cepas de bactérias como a Gluconacetobacter hansenii. A CB possui propriedades físicas e mecânicas únicas, morfologia tridimensional formada por uma rede de nanofibras, assim como um elevado grau de pureza, hidrofilicidade e biocompatibilidade comparada à celulose vegetal (Da Silva, 2012). Dos materiais sintéticos, um dos mais relevantes é o poli(L-ácido láctico) ou PLLA, um polímero sintético que tem como monômero estrutural o ácido láctico. Este material é importante tanto para aplicação na indústria dos plásticos, como na área médica (Garlotta, 2001; Kaihara et al., 2007), não só porque deriva de fontes renováveis e não tóxicas, mas também por ser biodegradável, bioabsorvível, de alta biocompatibilidade e de 
excelentes propriedades mecânicas (Wee et al., 2006; Kaihara et al., 2007).

Por seus atributos individuais, a CB e o PLLA apresentam um grande potencial para aplicações biomédicas, o que impulsiona o interesse pelo desenvolvimento de um biocompósito que reúna tanto as características da $\mathrm{CB}$ quanto as do PLLA. Assim, teve-se como objetivo produzir biocompósitos de PLLA e CB através da polimerização do PLLA in situ no interior do hidrogel de $\mathrm{CB}$ através do método de policondensação direta sem uso de catalisadores e caracterizar o biocompósito produzido por Espectroscopia no Infravermelho com Transformada de Fourier (FTIR), Microscopia Eletrônica de Varredura (MEV) e Termogravimétria (Tg/DTg).

\section{METODOLOGIA}

\subsection{Produção dos biocompósitos CB-PLLA}

Para a polimerização, L-ácido láctico comercial foi desidratado a vácuo a $105{ }^{\circ} \mathrm{C}$;, $\operatorname{logo}$ após foi oligomerizado por $3 \mathrm{~h}$ a $150{ }^{\circ} \mathrm{C}$, a vácuo. A seguir, hidrogéis de $\mathrm{CB}$ com formato de membranas e esferas foram adicionadas. A polimerização foi conduzida a $90{ }^{\circ} \mathrm{C}$, em condições de agitação e vácuo por $48 \mathrm{~h}$. Amostragens foram feitas a cada $24 \mathrm{~h}$. As amostras foram submersas em metanol, lavadas em água destilada e secas logo após.

\subsection{Caracterização dos biocompósitos}

Espectroscopia no Infravermelho com Transformada de Fourier (FTIR): Utilizou-se um equipamento de infravermelho Bruker, Tensor 25, pertencente ao Laboratório de Materiais (LabMat) da UFSC. As amostras secas foram analisadas na região de 4000 a $450 \mathrm{~cm}^{-1}$, com resolução de $4 \mathrm{~cm}^{-1}$ e acessório de refletância total atenuada (ATR), em condições ambiente (De Souza, 2012).

Microscopia Eletrônica de Varredura (MEV): Seguindo a metodologia descrita por Berti (2012), as amostras foram congeladas a $-80^{\circ} \mathrm{C}$ por $24 \mathrm{~h}$ em um Freezer $-80^{\circ} \mathrm{C}$ (marca Nuaire, modelo NU-9483GC) e, logo após, liofilizadas por $48 \mathrm{~h}$ num liofilizador Liotop, modelo L101, no Laboratório de Tecnologias Integradas (InteLab/UFSC). Após a liofilização, as amostras foram mantidas num dessecador de vidro. A preparação das amostras e as análises de microscopia foram realizadas no Laboratório Central de Microscopia Eletrônica (LCME) da UFSC. As amostras liofilizadas foram fixadas sobre fitas de carbono aderidas a suportes de alumínio (stubs) e, posteriormente, metalizadas com ouro, para exame da superfície das miliesferas e membranas utilizadas, assim como a superfície de fratura (seção transversal). A microestrutura foi analisada em microscópio eletrônico de varredura JEOL JSM-6390LV, do LCME.

Análise termogravimétrica (TGA): Análises térmicas foram feitas através de curvas de TGA obtidas em uma termobalança SDT Q600 V20.9 Build 20, no Laboratório de Materiais Vitrocerâmicos (Vitrocer) da UFSC. Para esta análise, foram utilizados aproximadamente 10,0 mg de cada amostra, aquecidos de 25 até $500{ }^{\circ} \mathrm{C}$ a uma taxa de $10{ }^{\circ} \mathrm{C} \cdot \mathrm{min}^{-1} \mathrm{sob}$ atmosfera inerte de $\mathrm{N}_{2}$ (De Souza, 2012). 


\section{RESULTADOS}

\subsection{Interações Físico-Químicas nos Biocompósitos de PLLA-CB analisados por FTIR-ATR}

Análises de espectroscopia no infravermelho foram feitas para as amostras dos biocompósitos produzidos com 24 e 48 horas de polimerização, assim como para o controle de CB pura. Os espectros obtidos são apresentados na Figura 1.

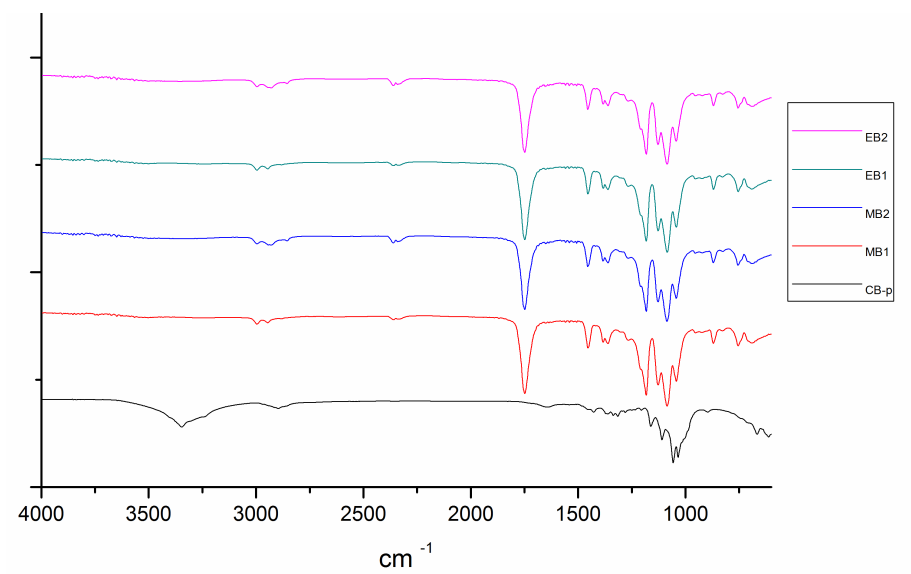

Figura 1 - Espectros de Infravermelho com ATR obtidos para amostras biocompósitas. EB1: Esferas biocompósitas polimerizadas por 24 h; EB2: Esferas biocompósitas polimerizadas por 48 h; MB1: Membranas biocompósitas polimerizadas por 24 h; MB2: Membranas biocompósitas polimerizadas por $48 \mathrm{~h}$; CB-p: Celulose bacteriana pura.

As atribuições das bandas do espectro de CB pura obtido neste trabalho são apresentadas na Tabela 1, de acordo as identificações reportadas por Gea e colaboradores (2010). Já as atribuções das bandas do espectro das amostras se apresentan na

Tabela 2. A identificação dos grupos funcionais foi feita com base nos trabalhos de Garlotta et al., (2001) e Gupta et al., (2007).

Tabela 1 - Atribuição dos picos de absorção de FTIR para controle de CB pura

\begin{tabular}{cc}
\hline Banda de absorção $\left(\mathbf{c m}^{-\mathbf{1}}\right)$ & Atribuição \\
\hline 3346 & $\mathrm{O}-\mathrm{H}$, estiramento \\
3244 & $\mathrm{O}-\mathrm{H}$, estiramento \\
2895 & $\mathrm{CH}_{2}$, estiramento assimétrico \\
1647 & Água absorvida \\
1635 & $\mathrm{C}(\mathrm{O}-\mathrm{H}($ da água absorvida $)$ \\
1427 & $(\mathrm{HCH}, \mathrm{OCH})$, torção \\
1362 & $\mathrm{CH}_{3}$, deformação \\
1161 & $(\mathrm{C}-\mathrm{O}-\mathrm{C})$, estiramento assimétrico \\
1109 & $(\mathrm{C}-\mathrm{C})$, estiramento $($ polissacarídeos, celulose $)$ \\
1057 & $(\mathrm{C}-\mathrm{O})$, estiramento \\
1034 & $(\mathrm{C}-\mathrm{O})$, torção \\
\hline
\end{tabular}


Tabela 2 - Atribuição dos picos de absorção de FTIR para as amostras compósitas de PLLACB produzidas por policondensação.

\begin{tabular}{ccc}
\hline \multicolumn{2}{c}{ Banda de absorção $\left(\mathbf{c m}^{\mathbf{- 1}}\right)$} & Atribuição \\
\hline $\mathbf{2 4}$ horas & $\mathbf{4 8} \mathbf{~ h o r a s}$ & \\
\hline 2993 & 2995 & $\mathrm{CH}$, estiramento assimétrico \\
2945 & 2928 & $\mathrm{CH}$, estiramento simétrico \\
\hline- & 2855 & $\mathrm{CH}$ \\
1747 & 1749 & $-\mathrm{C}=\mathrm{O}$, estiramento carbonila \\
1454 & 1456 & $\mathrm{CH} 2$, torção angular \\
1383 & 1383 & $\mathrm{CH}$, deformação simétrica \\
1361 & 1361 & $\mathrm{CH}$, deformação assimétrica \\
1182 & 1182 & $(-\mathrm{C}-\mathrm{O}-)$, estiramento \\
1128 & 1128 & \\
1086 & 1086 & $\mathrm{O}-\mathrm{H}$, torção \\
1043 & 1043 & $(-\mathrm{C}-\mathrm{C}-$ ), estiramento \\
\hline 870 & 869 & \\
\hline
\end{tabular}

Avaliando o espectro dos biocompósitos EB1, EB2, MB1 e MB2, foi observado que as principais bandas de absorção detectadas correspondiam ao estiramento do grupo funcional $\mathrm{C}=\mathrm{O}$ e ao estiramento do grupo $\mathrm{C}-\mathrm{O}$. Comparando os resultados obtidos de todas as amostras com os dados reportados na literatura para o PLLA puro, observou-se que em todos os casos os biocompósitos apresentam um espectro de absorção semelhante ao do PLLA em sua forma pura. Isso evidencia a formação de poli(L-ácido láctico) e, em consequência, a produção de biocompósitos de poli(L-ácido láctico) e celulose bacteriana mediante o processo de polimerização sugerido.

\subsection{Distribuição das fibras de celulose bacterina no biocompósito}

Na Figura 2 são apresentadas as micrografias dos controles de CB com formato de esfera e membrana obtidas no LCME da UFSC. Observa-se que as miliesferas de CB têm microestrutura externa diferente da microestrutura interna, sendo que no interior a densidade das fibras é maior, comparada com a do exterior. No caso das membranas, mostra-se que possuem uma superfície formada por um arranjo altamente denso de nanofibras de CB (lado denso) e a outra superfície possui um arranjo anisotrópico e poroso de nanofibras de CB (lado poroso) como já relatado por Bäckdahl e colaboradores (2006) e Berti (2012).

Amostras dos biocompósitos produzidos foram também analisadas por MEV. Obtiveram-se micrografias dos compósitos com formato de membranas e miliesferas polimerizadas por 24 e $48 \mathrm{~h}$. A partir das imagens geradas, é possível observar que a microestrutura da CB foi modificada e um novo material foi produzido. Esta situação se repetiu para todos os biocompósitos, tanto com formato de membrana quanto de esfera, nos dois tempos de polimerização. As micrografias obtidas dos biocompósitos de 24 h de polimerização são mostradas na Figura 3 (membranas) e na Figura 4 (esferas). Em todos os casos, observa-se que os poros formados pela rede de nanofibras que conformam os hidrogéis de CB (Figura 2) foram preenchidos com um material que aparenta ter uma massa regular e lisa, semelhante à do PLLA puro. 


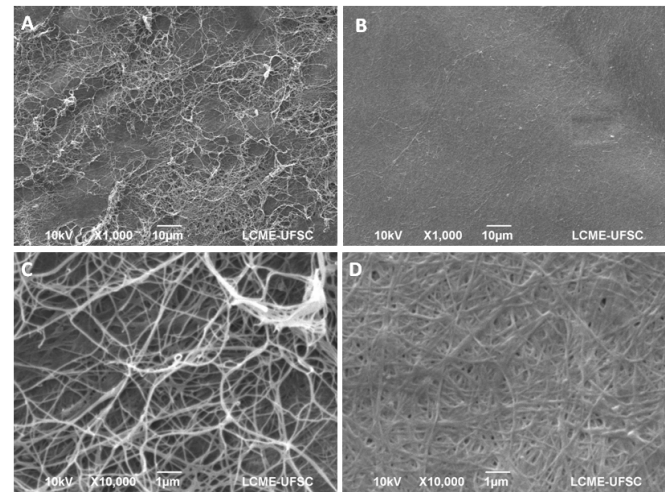

Figura 2 - Micrografias de miliesferas e membranas de celulose bacteriana puras liofilizadas com ampliação de 1000×: A) Superfície externa da esfera. B) Superfície interna da esfera. C) Lado inferior da membrana. D) Lado superior.

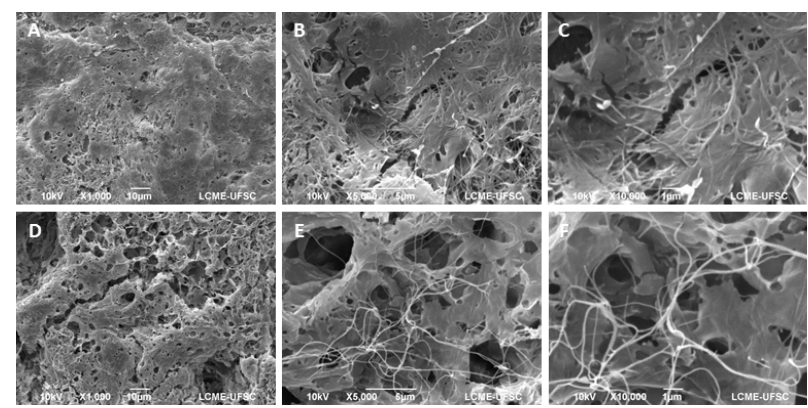

Figura 3 - Micrografias das duas superfícies dos biocompósitos com formato de membrana produzidos após 24 horas de polimerização. As imagens $\mathrm{A}, \mathrm{B}$ e $\mathrm{C}$ correspondem à mesma superfície com ampliações de $1000 \times, 5000 \times$ e $10000 \times$, respectivamente. Por sua vez as imagens $(\mathrm{D}),(\mathrm{E})$ e $(\mathrm{F})$ correspondem à superfície oposta nas mesmas ampliações.
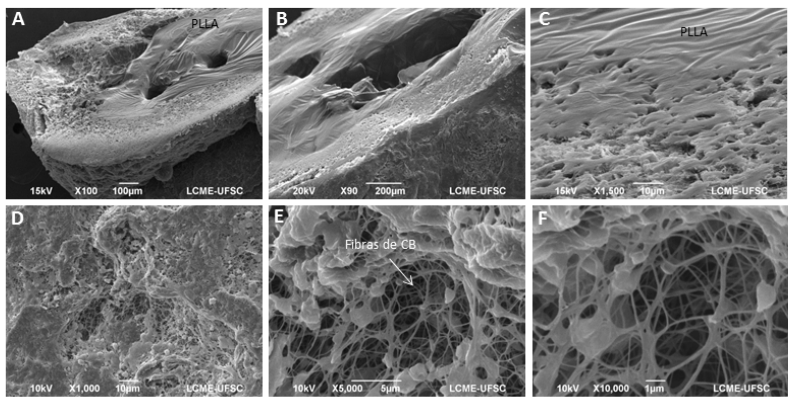

Figura 4 - Micrografias de biocompósitos CB-PLLA com formato de esfera produzidos após 24 horas de polimerização. As imagens A, B e C correspondem ao corte transversal da amostra, para diferentes ampliações. Por sua vez, as imagens (D), (E) e (F) correspondem à superfície externa dos biocompósitos em diferentes ampliações.

Nas membranas biocompósitas as superfícies de cada um dos seus lados apresentaram-se diferentes, preservando as assimetrias observadas nas membranas-controle (CB pura). No caso das miliesferas, observa-se que o centro foi preenchido pela massa de polímero produzido e que essa 
massa vai se estendendo desde o centro para a superfície exterior, sendo esta mais porosa. Em algumas regiões é facilmente identificada a presença das nanofibras de celulose nas ampliações de $10000 \times$. Nas imagens, verifica-se que estas estão presas dentro da matriz de PLLA formada. Verifica-se também uma boa dispersão, já que as amostras parecem ter conservado sua distribuição original dentro da matriz formada. Cabe destacar que não se observaram aglomerações das fibras de celulose, um fator positivo uma vez que, como descrito por Raquez e colaboradores (2013), a hidrofilicidade das nanofibras de celulose, tanto as de origem vegetal quanto bacteriana, dificulta a produção de biocompósitos com fibras de celulose em uma matriz hidrofóbica como o PLLA, principalmente pela dificuldade de se conseguir uma boa dispersão das fibras na matriz.

\subsection{Estabilidade térmica dos biocompósitos de PLLA-CB}

Os resultados do teste termogravimétrico são apresentados na Tabela 3. A avaliação do perfil das curvas termogravimétricas derivadas indica um comportamento de decomposição em três etapas. O primeiro evento está relacionado à perda de água superficial das amostras, permitindo a observação de um evento térmico na faixa de 60 a $70{ }^{\circ} \mathrm{C}$, e uma perda de massa de aproximadamente 1,6\%. Possivelmente, este evento foi ocasionado pelas fibras de $\mathrm{CB}$ presentes nos biocompósitos, uma vez que, como foi observado por De Souza (2012), a CB pura apresenta eventos endotérmicos a $70^{\circ} \mathrm{C}$, causados pela evaporação da água superficial, e apresenta uma perda de massa de 4,5 a 7,5\%.

$\mathrm{Na}$ faixa de 300 a $360{ }^{\circ} \mathrm{C}$ observaram-se outros dois eventos térmicos, tanto para as amostras com formato de esfera (miliesferas) quanto de membrana. O primeiro pico pode ser atribuído à $\mathrm{CB}$, uma vez que as curvas de DTG para CB-p reportadas na literatura evidenciam uma temperatura de degradação máxima na faixa dos 300 a $350{ }^{\circ} \mathrm{C}$. Por sua vez, o terceiro evento corresponde à temperatura máxima de degradação do PLLA, como observado por Murariu e colaboradores (2010), tendo em vista que esta temperatura está na faixa de 330 a $390{ }^{\circ} \mathrm{C}$.

Tabela 3 - Temperaturas de degradação térmicas obtidas por TGA

\begin{tabular}{ccccccccc}
\hline Amostra & $\begin{array}{c}\mathbf{T}_{\text {onset1 }} \\
\left({ }^{\circ} \mathbf{C}\right)\end{array}$ & $\begin{array}{c}\mathbf{T}_{\max \mathbf{1}} \\
\left({ }^{\circ} \mathbf{C}\right)\end{array}$ & $\begin{array}{c}\text { Perda de } \\
\text { massa }_{\mathbf{1}}(\mathbf{\%})\end{array}$ & $\begin{array}{c}\mathbf{T}_{\text {onset 2 }} \\
\left({ }^{\circ} \mathbf{C}\right)\end{array}$ & $\begin{array}{c}\mathbf{T}_{\max 2} \\
\left({ }^{\circ} \mathbf{C}\right)\end{array}$ & $\begin{array}{c}\mathbf{T}_{\text {onset 3 }} \\
\left({ }^{\circ} \mathbf{C}\right)\end{array}$ & $\begin{array}{c}\mathbf{T}_{\max 3} \\
\left({ }^{\circ} \mathbf{C}\right)\end{array}$ & $\begin{array}{c}\text { Perda de } \\
\text { massa }_{\mathbf{2}}(\mathbf{\%})\end{array}$ \\
\hline MB1 & 70,43 & 84,39 & 1,30 & 252,60 & 309,60 & 314,64 & 351,27 & 98,26 \\
MB2 & 69,81 & 92,03 & 1,95 & 251,18 & 313,66 & 318,72 & 356,26 & 96,39 \\
EB1 & 67,30 & 83,94 & 1,21 & 245,65 & 310,59 & 315,57 & 353,72 & 96,89 \\
EB2 & 69,77 & 93,01 & 1,98 & 248.80 & 315,13 & 321,75 & 357,63 & 96,45 \\
\hline
\end{tabular}

Como sugerido por Siqueira (2011), a temperatura de degradação que foi considerada para os biocompósitos é a equivalente ao maior pico na curva DTG, ou seja, $\mathrm{T}_{\max 3}$ da Tabela 3. Observou-se também que a massa é estável no intervalo entre 98,5 e $150{ }^{\circ} \mathrm{C}$, tanto para os biocompósitos de $24 \mathrm{~h}$ como de $48 \mathrm{~h}$ de polimerização, pelo que pode se assumir que este é um intervalo de temperatura adequado para o processamento dos biocompósitos produzidos. 


\section{CONCLUSÕES}

É possível produzir PLLA dentro de hidrogéis de celulose bacteriana, in situ, sem o uso de catalisadores. Os biocompósitos de PLLA/CB produzidos apresentaram uma microestrutura diferente da de CB e PLLA puros. As nanofibras de celulose ficam presas no interior da matriz de PLLA formada, conservando sua distribuição original, promovendo uma boa dispersão no biocompósito. A análise térmica determinou que a faixa de temperatura de processamento dos biocompósitos produzidos fica no intervalo entre 98,5 e $150{ }^{\circ} \mathrm{C}$, uma vez que nesta faixa de temperatura não há considerável perda de massa.

\section{REFERÊNCIAS}

BÄCKDAHL, H.; HELENIUS, G.; BODIN, A.; NANNMARK, U.; JOHANSSON, B. R.; RISBERG, B.; GATENHOLM, P. Mechanical properties of bacterial cellulose and interactions with smooth muscle cells. Biomaterials, v. 27, n. 9, p. 2141-2149, 2006.

BERTI, F. V. Desenvolvimento de estruturas vasculares endotelizadas em scaffolds de celulose bacteriana. 2012. 147 Tese (Doutor em Engenharia Química). Programa de PósGraduação em Engenharia Química, Universidade Federal de Santa Catarina, Florianópolis, 2012.

CHENG, Y.; DENG, S.; CHEN, P.; RUAN, R. Polylactic acid (PLA) synthesis and modifications: a review. Frontiers of Chemistry in China, v. 4, n. 3, p. 259-264, 2009.

DA SILVA, T. R. S. Desenvolvimento de hidrogéis de celulose bacteriana para cultura de células e permeação de biomoléculas. 2012. 140 Dissertação (Mestre em Engenharia Química). Programa de Pós-Graduação em Engenharia Química, Universidade Federal de Santa Catarina, Florianópolis.

DE SOUZA, D. J. Estudo de biocompósitos de poli(L-ácido láctico (PLLA) com celulose bacteriana visando aplicação como membranas biomédicas. 2012. Trabalho de Conclusão de Curso (Engenheiro Químico). Engenharia Química, Universidade da Região de Joinville (UNIVILLE), Joinville.

GARLOTTA, D. A literature review of poly(lactic acid). J. Polym. Environ., v. 9, n. 2, p. 6384, Apr 2001.

GUPTA, B.; REVAGADE, N.; HILBORN, J. Poly(lactic acid) fiber: An overview. Prog. Polym. Sci., v. 32, n. 4, p. 455-482, Apr 2007.

JARDINI, A. L.; LUNELli, B. H.; MARTINEZ, G. A. R.; LASPRILlA, A. J. R.; DA SILVA, J. V. L.; FILHO, R. M. Computer-Aided Tools for Modeling and Simulation in the Biomaterials Production. Latin American Congress of Artificial Organs and Biomaterials (COLAOB). Gramado, Brasil 2010. 
JOHN, R.; NAMPOOTHIRI, K.; PANDEY, A. Fermentative production of lactic acid from biomass: an overview on process developments and future perspectives. Appl. Microbiol. Biot., v. 74, n. 3, p. 524-534, 2007.

KAIHARA, S.; MATSUMURA, S.; MIKOS, A. G.; FISHER, J. P. Synthesis of poly(Llactide) and polyglycolide by ring-opening polymerization. Nat. Protoc., v. 2, n. 11, p. 27672771, 2007.

KLAUSS, P. Desenvolvimento de dispositivos poliméricos implantáveis para a liberação de fármaco fabricados por sinterização seletiva a laser. 2010. 174 Tese (Doutor). Programa de Pós-Graduação em Ciência e Engenharia de Materiais, Universidade Federal de Santa Catarina, Florianópolis.

LOPES, M. S.; JARDINI, A. L.; FILHO, R. M. Poly (Lactic Acid) Production for Tissue Engineering Applications. Procedia Engineering, v. 42, n. 0, p. 1402-1413, 2012.

MURARIU, M.; BONNAUD, L.; YOANN, P.; FONTAINE, G.; BOURBIGOT, S.; DUBOIS, P. New trends in polylactide (PLA)-based materials: "Green" PLA-Calcium sulfate (nano)composites tailored with flame retardant properties. Polym. Degrad. Stabil., v. 95, n. 3, p. 374-381, 2010.

RAQUEZ, J.-M.; HABIBI, Y.; MURARIU, M.; DUBOIS, P. Polylactide (PLA)-based nanocomposites. Prog. Polym. Sci., v. 38, n. 10-11, p. 1504-1542, 2013.

SIQUEIRA, J. D. F. Prospecção e síntese de poli(ácido láctico) para desenvolvimento de suportes na engenharia tecidual 2011. (Mestrado). Faculdade de Engenharia Química - FEQ, Universidade Estadual de Campinas Campinas, SP.

WEE, Y. J.; KIM, J. N.; RYU, H. W. Biotechnological production of lactic acid and its recent applications. Food Technol. Biotech., v. 44, n. 2, p. 163-172, Apr-Jun 2006. 